\title{
1. The social dimensions of climate change
}

\section{CLIMATE CHANGE AND HUMAN WELLBEING}

Climate change threatens human wellbeing across the world and into the future. It poses an existential challenge with no past parallels: 'a truly complex and diabolical policy problem' (Steffen 2011). Human wellbeing obviously depends on Earth's support systems, and these are many and varied and, crucially, interactive. For the past 10000 years the Holocene - these systems have maintained a relatively stable state, forming the ecological foundations for the emergence of human civilisation. Now a new geological epoch, the Anthropocene, has been identified, where human activities start to have a significant - and negative - global impact on Earth's ecosystems.

The Stockholm Resilience Centre has identified nine critical Earth-system processes: climate change, the rate of biodiversity loss, the nitrogen and phosphorus cycles, stratospheric ozone, ocean acidity, global freshwater supplies, agricultural land availability, atmospheric aerosol loading, and chemical pollution. It goes on to estimate safe boundaries for each and concludes that the first three of these 'planetary boundaries' have already been crossed. Climate change - the change in energy in the atmosphere due to greenhouse gas emissions (the degree of 'radiative forcing') - already exceeds safe boundaries (Rockström et al. 2009). As I finish this chapter, two news reports have announced that 2016 will be the warmest year ever recorded, following on from the previous warmest, 2015, and that temperatures over the Arctic are an astonishing $20^{\circ} \mathrm{C}$ higher than normal.

Of these limits, this book is concerned only with climate change. Choosing just one of the nine ecological boundaries is not without problems: it can sideline major socio-ecological issues such as food, water and the state of the oceans. The choice is partly due to lack of time, space and knowledge. But it also reflects a consensus that climate change is the great 'threat multiplier', posing the most immediate, serious and intractable threat to human wellbeing in today's world. It is this relationship between human wellbeing and climate change that is the primary focus of the book. 


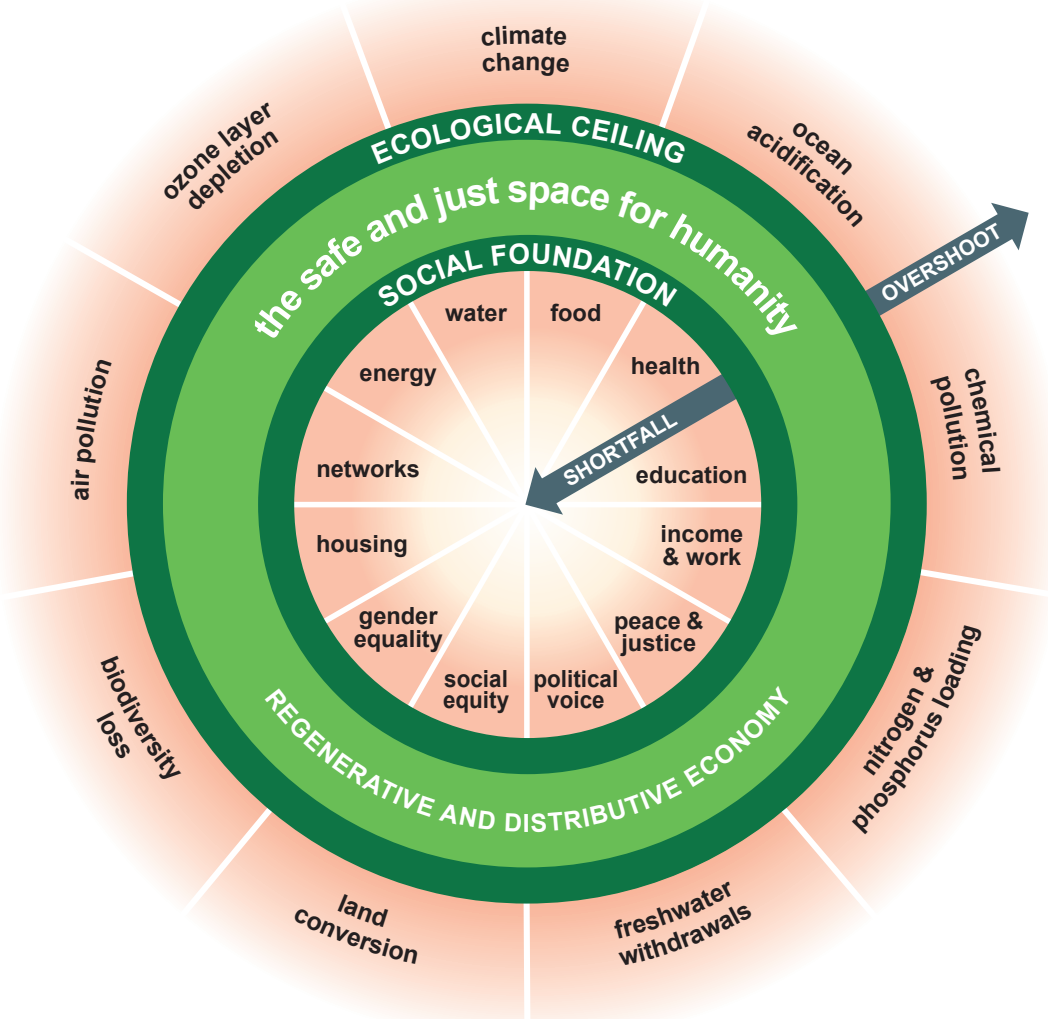

Source: Raworth (2017: 44).

Figure 1.1 A safe and just space for humanity to thrive in: a first illustration

Kate Raworth pictures the interaction of planetary boundaries and human wellbeing as a 'doughnut' or 'lifebelt', illustrated in Figure 1.1.

The nine planetary boundaries described by the Stockholm Resilience Centre constitute the outer circle (Rockström et al. 2009). The social foundations of human wellbeing constitute the inner boundary, drawing on the 'Sustainable Development Goals' formally accepted by the United Nations General Assembly in 2015. The exact nature of these components of human welfare will be discussed below and in Chapter 2 .

The most urgent global task is to bring everyone above the social foundations which guard against threatening social deprivations while 
not exceeding the critical planetary boundaries - which will in turn guard against future generations falling below these social foundations.

Between a social foundation that protects against critical human deprivations, and an environmental ceiling that avoids critical natural thresholds, lies a safe and just space for humanity - shaped like a doughnut (or, if you prefer, a tyre, a bagel, or a life saver). This is the space where both human well-being and planetary well-being are assured, and their interdependence is respected ... Moving into the safe and just space for humanity means eradicating poverty to bring everyone above the social foundation, and reducing global resource use, to bring it back within planetary boundaries. Social justice demands that this double objective be achieved through far greater global equity in the use of natural resources, with the greatest reductions coming from the world's richest consumers. And it demands far greater efficiency in transforming natural resources to meet human needs. (Raworth 2012: 5, 12)

Yet there is profound disjuncture between the ecological and social imperatives. The planetary boundaries remained unviolated in the Holocene for about 10000 years until recently. But there have always been, and there remain, millions of people in dire need, hungry, sick, impoverished, threatened, insecure, harmed in numerous objective ways and suffering in innumerable personal and collective ways. It is quite conceivable to pursue programmes for planetary sustainability without tackling this backlog of unmet needs; indeed there are many ways in which climate policies may harm the poor and worsen global inequality. For the moment, I simply assert that there are profound moral and consequential arguments for linking the two together and tackling both at once.

This book places the social dimension of wellbeing firmly in the centre of discussions about climate change - and vice versa. This chapter sets the scene by first summarising our best knowledge about the past, present and predicted future(s) of global warming. Second, it sketches the likely impacts of future climate change on human habitats and human welfare. Third, it summarises the options for climate policy, in terms of mitigating climate change and adapting to it. Fourth, it looks in more detail at the inner ring of Raworth's lifebelt and considers how far the Sustainable Development Goals agreed in 2015 provide a framework for conceiving and measuring these policy options.

\section{THE CHALLENGES OF CLIMATE CHANGE}

The Intergovernmental Panel on Climate Change (IPCC) brings together the majority of climate scientists in the world and issues reports of the global scientific consensus, the latest being the Fifth Report, published 
in 2013/14. It marks an unprecedented mobilisation of scientific cooperation, and provides a benchmark of current best knowledge on which to draw (see also Royal Society 2010). The arguments of climate deniers, still powerful in a few countries (mainly in the 'Anglosphere', and notably the US), are not considered here. However, their role is discussed in places as a feature of political and ideological efforts to block and delay attempts to curb climate change.

In summary, mean global temperatures are now about $1.0{ }^{\circ} \mathrm{C}$ higher than nineteenth-century levels. The 2014 IPCC Summary Report states:

Warming of the climate system is unequivocal, and since the 1950s many of the observable changes are unprecedented over decades to millennia. The atmosphere and oceans have warmed, the amounts of snow and ice have diminished and sea level has risen ... Atmospheric concentrations of carbon dioxide $\left(\mathrm{CO}_{2}\right)$, methane and nitrous oxide are unprecedented in at least the last 800,000 years. (IPCC 2014a: 1, 4)

The scientific link between this warming and certain atmospheric emissions - labelled 'greenhouse gases' (GHGs) - has been established for over a century. The most significant is carbon dioxide or $\mathrm{CO}_{2}$, which accounts for three-quarters of the total and is growing. $\mathrm{CO}_{2}$ is mainly the product of burning fossil fuels (almost 80 per cent) and of certain industrial processes such as cement production, refineries, the iron and steel industry and the petrochemical industry. The remaining quarter of anthropogenic $\mathrm{GHG}$ emissions are non- $\mathrm{CO}_{2}$ gases, notably methane and nitrous oxide stemming from agriculture and other human uses of land.

Future global warming will depend on the cumulative stock of greenhouses gases in the atmosphere. All GHGs stay in the atmosphere and thus contribute to global warming for some time, but the time period differs. Methane, though a potent GHG, lasts only about 12 years, but 'carbon is forever'. A total of 65-80 per cent of $\mathrm{CO}_{2}$ released into the air dissolves slowly into the ocean over a period of 20-200 years; the remainder can take up to several hundreds or thousands of years to disappear. Given this fact, it is the total carbon budget - the cumulative total of emissions - that matters, not the target for some year in the future, such as 2050. The IPCC (2014a: 8) concludes: 'Multiple lines of evidence indicate a strong, consistent, almost linear relationship between cumulative $\mathrm{CO}_{2}$ emissions and projected global temperature change to the year 2100.' In the absence of effective climate action the major driver of this climatic shift will be cumulative emissions of $\mathrm{CO}_{2}$, which will 'largely determine global mean surface warming by the late 21 st century and beyond'.

Current predictions by the IPCC (2013: 10) are pessimistic: 
Surface temperature is projected to rise over the 21st century under all assessed emission scenarios. It is 'very likely' that heat waves will occur more often and last longer, and that extreme precipitation events will become more intense and frequent in many regions. The ocean will continue to warm and acidify, and global mean sea level to rise. (IPCC 2013: 10)

Moreover, most aspects of climate change will persist for many centuries even if emissions of $\mathrm{CO}_{2}$ are stopped. Past, present and future emissions of $\mathrm{CO}_{2}$ commit us to mitigation action for centuries to come.

\section{HUMAN IMPACTS}

The IPCC goes on to analyse the likely impacts of global warming on a) ecosystems and b) human welfare, using integrated assessment models (IAMs). Impacts clearly attributable to climate change, as opposed to other causes, include: permafrost warming and thawing in high-latitude and high-elevation regions; shifts in the geographical ranges of many terrestrial, freshwater and marine species; negative impacts on crop yields (exceeding positive impacts); and impacts of recent climate-related extremes - such as heatwaves, droughts, floods, cyclones and wildfires - on many human systems (IPCC 2014b: 4-6).

The uncertainties involved in such modelling should always be borne in mind. The wide range in predicted temperatures has been noted, but the uncertainties multiply when forecasting things like crop yield changes and impacts on biodiversity, and still more when estimating human impacts and the effects of climate-related strategies. The predictions depend on at least three estimations: first, the extent to which impacts can be attributed to future climate change; second, assumptions about the impacts of current and future mitigation strategies; and, third, assumptions about the impacts of current and future adaptation strategies (IPCC 2014b: 8).

This global modelling is the starting point for most studies of the impacts of climate change on human habitats and human welfare. Another useful approach focuses on social vulnerability, starting from the local development context in which climate change occurs. The social and health impacts of climatic hazards are always mediated by the vulnerabilities of populations and their capacities to 'respond, recover and prepare' (O’Neill 2016). This will depend on a wide range of factors, including personal factors such as age or health, community factors such as the intensity and support of social networks, and societal-level factors such as the distribution of wealth and power, the strength of solidarity and the robustness of collective institutions. If we are to capture the new social 
risks and threats to wellbeing resulting from climate change we need to combine both approaches (IPCC 2014c).

The IPCC (2014b) Second Working Group Report on Human Impacts covers a wide range of issues: freshwater resources, terrestrial and inland water systems, coastal systems and low-lying areas, ocean systems, food security and food production systems, urban areas, rural areas, key economic sectors and services, human health, human security, livelihoods and poverty. I will briefly consider just a few of these.

It is projected that global food security will be undermined by climate change. Wheat, rice and maize production in temperate regions will be negatively affected, though some higher latitudes will benefit from a longer crop season. Water resources will decrease in most dry subtropical regions. Sustainable fisheries will be threatened by a redistribution of marine species and a reduction in biodiversity. Tropical regions will be disadvantaged by the redistribution of potential fisheries towards higher latitudes.

Health will be affected directly by changes in temperatures and weather systems, indirectly by changing disease vectors and crop patterns, and also by social responses to these shifts, such as population displacement. Impacts include a greater likelihood of disease and death due to heatwaves and fires, as well as from food- and water-borne diseases. The increased threats to food security may result in more under-nutrition, especially in developing countries with low incomes. Vulnerable populations may also face reductions in work capacity and labour productivity, which can in turn affect health.

In terms of livelihoods and poverty climate change will act as a "threat multiplier': poor, marginal and socially excluded groups will suffer more, with the deepest impacts likely to be felt in sub-Saharan Africa and South Asia. Higher food prices are particularly likely to affect households depending on wage labour that are net buyers of food, especially in urban areas. Extreme weather events, as well as flooding due to rising sea levels, will threaten the territorial integrity of small islands and states with extensive low coastlines. There is considerable historical evidence suggesting that changes in climatic conditions have already been a contributory factor in migration. This includes large population displacements in the wake of severe events such as the northern Ethiopian famines of the 1980s, Hurricane Mitch in Central America in 1998 and Hurricane Katrina in New Orleans in 2005. On the other hand vulnerability is inversely correlated with mobility: those most exposed and vulnerable to the impacts of climate change have the least capability to migrate. The resulting 'trapped populations' may well suffer more than migrants (Foresight 2011; IPCC 2014b). Other results, such as conflicts over scarce water resources, have the potential to increase rivalry between states. 
People, assets and ecosystems in urban areas are likely to suffer the consequences of heat stress, extreme precipitation, flooding, landslides, air pollution, droughts and water scarcity. Exposed areas and populations living in poor housing conditions will once again be most at risk. Rural areas will also be affected by these weather events, as well as by changes in agricultural incomes and access to water. Those communities with limited access to land and to modern agricultural technologies and infrastructure are expected to be most negatively affected (IPCC 2014b).

In a previous report the IPCC (2007) concluded that climate change will impact most heavily on tropical and subtropical regions, where standards of living are in general lower. The Fifth Report is less willing than previous reports to draw together these risks into an overall global pattern of climate vulnerability. However, it does repeat that risks are 'generally greater for disadvantaged people and communities in countries at all levels of development'. The following 'hotspots' are identified: the Mediterranean Basin, Central America, Central and West Africa, northern high-latitude regions, the Amazon, south/west US, South-East Asia, and the Tibetan Plateau (IPCC 2014b). And the report highlights two 'unique and threatened systems' subject to very high risks with additional warming of $2{ }^{\circ} \mathrm{C}$ : the Arctic sea ice and coral-reef systems (IPCC 2014b: 12).

In conclusion, the IPCC Report is unambiguous: 'Continued emission of greenhouse gases will cause further warming and long-lasting changes in all components of the climate system, increasing the likelihood of severe, pervasive and irreversible impacts for people and ecosystems. Limiting climate change would require substantial and sustained reductions in greenhouse gas emissions' (IPCC 2014a: 8, italics added).

If current mitigation policies prove inadequate and we head for a $4{ }^{\circ} \mathrm{C}$ warmer world, then the prospects for humanity are dire according to the World Bank (2012): 'If the global community fails to act on climate change it will trigger a cascade of cataclysmic changes that include extreme heat-waves, declining global food stocks and a sea-level rise affecting hundreds of millions of people.'

Kevin Anderson (2012) warns that $4{ }^{\circ} \mathrm{C}$ is 'incompatible with any reasonable characterisation of an organized, equitable and civilized global community'. And Lord Stern, Head of the 2006 Stern Review on the Economics of Climate Change, writes:

Five degrees is absolutely enormous. It would redraw the physical geography of the world. Large parts of the world would become desert, including most of southern Europe and the southern part of France. Other areas would be inundated. You'd see massive movements of population ... This isn't a black swan, a small probability of a big problem; this is a big probability of a huge problem. (In Kaul et al. 2009: 136) 
It is not surprising that 'end times' and dystopian futures are a growing feature of fiction and other art forms in this new millennium (Hamilton 2010; Urry 2011).

\section{Unequal Contributions to Climate Change}

The sources and drivers of emissions are discussed further in Chapter 3. For the moment they can be summarised as follows.

First, the bulk of the cumulative stock of $\mathrm{CO}_{2}$ in the atmosphere has been contributed by the rich industrialised world: the burning of fossil fuels has precisely been a major source of their wealth. Since 1850 , over one-half of the global total has been emitted by the US and Europe. Because $\mathrm{CO}_{2}$ remains in the atmosphere for many generations, cumulative emissions remain an important measure of responsibility for global warming.

However, second, in recent years the annual emissions of emerging market economies, most notably China, have expanded fast and overtaken those of the developed world, which have remained stable. China is now the world's largest annual emitter of $\mathrm{CO}_{2}$.

But, third, there is a growing discrepancy between the emissions from a given national territory (production-based emissions) and the 'consumption footprint' of a given national territory (consumption-based emissions). Consumption-based emissions of the OECD are higher than their territorial emissions, while those of the rest of the world are lower. This reflects the outsourcing of manufacturing and industry from the West to the East during the period of intense globalisation - and accompanying deindustrialisation in the West - since around 1980. Consumption emissions of the West continued to rise - until the sharp fall occasioned by the severe financial crisis and recession of 2007-09. The West has gained doubly: both from rising consumption and from an apparently declining responsibility for the associated emissions. There has been 'environmental load displacement' from North to South (Christoff and Eckersley 2013).

Fourth, these country totals make little sense without taking into account their populations (though it is interesting how often this simple fact is ignored: one might as well praise tiny Luxembourg for its commendable emissions record when in fact it has the highest emissions per person in the world). When this is done, emissions per person reveal wide inequalities, especially when calculating consumption-based emissions: North Americans emit on average 22 tonnes of $\mathrm{CO}_{2}$ a year, West Europeans 13 tonnes, Chinese 6 tonnes and South Asians and Africans 2 tonnes (Chancel and Piketty 2015). These gaps are closing, but at a slow pace.

Finally, predicted future annual emissions show parts of the developing 
world overtaking the developed. The national contributions to the accumulated stock of emissions will follow a similar pattern but with a lag.

Putting together national and regional responsibilities for global warming with its national and regional impacts reveals a global double injustice (Gough 2011a). Consumers in the richer countries of the West still account for about one-half of cumulative greenhouse gases and enjoy on average considerably higher standards of living than the rest of the world. Yet on balance they are predicted to suffer fewer negative climatic impacts over the next two decades. Indeed some areas, such as Northern Europe, could benefit from longer growing seasons and lower heating costs. Tropical and sub-tropical areas with lower incomes and few past responsibilities for emissions will suffer major negative impacts.

The globalisation of the world economy that has brought this about suggests that the old duopoly of 'global North' and 'global South' is no longer appropriate when discussing global climate patterns. To reflect this, in the rest of the book I will use instead a threefold distinction between North, East and South:

- The North comprises the original OECD member states and some developed newer members (e.g. South Korea).

- The 'East' comprises the fast-emerging economies including the BRIC countries (Brazil, Russia, India, China) and the MINT countries (Mexico, Indonesia, Nigeria, Turkey).

- The South comprises the developing world of low-income and low-middle-income countries, mainly in Africa, Asia and parts of Latin America.

These terms make no geographical sense - of course Australia is not in the north, Brazil and Mexico are not in the east - but all nomenclatures have problems and these have the virtue of brevity.

\section{CLIMATE POLICY}

Standing between this powerful dynamic of growing emissions and the dangerous consequences of global warming are a range of 'climate policies', at global, regional, national, sub-national and sectoral levels. Figure 1.2 offers a very simplified portrayal of the complex links between the causes of growing emissions and the impacts on human wellbeing. This helps to distinguish three categories of climate policies.

Climate mitigation policy refers to human interventions to reduce the sources, or enhance the 'sinks', of greenhouse gases. Broadly speaking, 


\section{Economic activity -> \\ Energy consumption -> \\ Greenhouse gas emissions -> -> Absorption by GHG sinks \\ GHG cumulative concentrations -> \\ Global temperature rise -> \\ Regional and local climate change -> Impact on human habitats -> \\ Human wellbeing}

\section{Figure 1.2 From human activity to climate change to human wellbeing}

mitigation policies target the first three rows of Figure 1.2: to reduce emissions and enhance global carbon sinks, requiring shifts in energy policy and, further upstream, the scale and nature of economic activity. The language of mitigation is used rather than 'prevention', in recognition of the fact that further global warming cannot be prevented owing to the accumulation of past GHGs in the atmosphere.

Climate adaptation policy seeks to lower the risks posed by the consequences of climatic changes. Adaptation policies target the last two rows of the figure to reduce risks to habitats and human wellbeing. Clearly a combination of mitigation and adaptation interventions will be necessary to forestall harmful impacts on human populations.

In between the two there is a potential third domain of interventions designed to directly target cumulative GHG concentrations, global temperature rise and regional climate change. This is the arena of geoengineering, deliberate large-scale interventions in the Earth's natural systems to counteract climate change, for example by reflecting part of the sun's energy back into space or directly removing $\mathrm{CO}_{2}$ from the atmosphere. Geo-engineering is beginning to enter policy debate, but the current consensus is that it is fraught with unforeseeable and potentially catastrophic consequences and I do not discuss it further here. 'We should remain under no illusion that if we have to resort to these kinds of technologies, then humankind is in a mess' (Berners-Lee and Clark 2013; cf. Royal Society 2010).

\section{Mitigation}

Mitigation plays a central role in Article 2 of the United Nations Framework Convention on Climate Change (UNFCCC), which aims for 'stabilisation of greenhouse gas concentrations in the atmosphere at a level that would prevent dangerous anthropogenic interference with the climate system'. The Copenhagen Accord was endorsed by 167 countries, agreeing that the 
safest maximum amount that global temperatures should be allowed to rise above the pre-industrial level is $2{ }^{\circ} \mathrm{C}$. To achieve this, the Paris agreement in December 2015 calls for zero net anthropogenic GHG emissions to be reached during the 'second half of the 21 st century'. In addition nations at Paris agreed to drive efforts to limit the temperature increase to no more than $1.5^{\circ} \mathrm{C}$ above pre-industrial levels (UNFCCC 2015).

This is a safer but dauntingly ambitious goal. According to Lord Stern (2015), to achieve (only) a 50:50 chance of avoiding global warming exceeding $2{ }^{\circ} \mathrm{C}$ by the end of the century, and taking population growth into account, global emissions must be cut from around 7 tonnes $\mathrm{CO}_{2} \mathrm{e}^{1}$ per person per year now to no more than 2 tonnes by 2050 - a revolutionary downshift of 3.5 times. But, if output per person continues to grow at its present rate (roughly trebling by 2050), then global emissions per unit of output must fall by a factor of 7-8 times by 2050 - as I write now only 33 years away.

Moreover, the risks of modelling a 50:50 chance are self-evident. Bill McKibben (2012) has taken to task other models using a 'reasonable 20\%' risk, pointing out that 'reasonable' in this case means 'one chance in five, or somewhat worse odds than playing Russian roulette with a six-shooter'. A 50:50 chance is like playing Russian roulette with bullets in three chambers.

The range of potential mitigation interventions is enormous. A short list would include: reducing fossil fuel extraction; pricing carbon; fostering renewable energy technology, alternative fuels and alternative transport systems and mobility structures; investing in new technology and energy efficiency; encouraging net forestation, changes in rural land use and agricultural practices (management of croplands, grazing lands and soil restoration); managing urban forms and land use; building infrastructure and spatial planning; designing buildings for energy efficiency; and changing consumer behaviour, lifestyle and culture (IPCC 2014c). Some of these will be encountered and analysed in this book.

Taking just the first of the list above, research by Carbon Tracker estimates that the world could emit about 900 gigatonnes (Gt) (billions of tonnes) of $\mathrm{CO}_{2}$ between 2000 and 2050 (of which 17 years have now elapsed) and still have a 'reasonable' chance of avoiding $2{ }^{\circ} \mathrm{C}$ warming (Ranger and Ward 2013). These figures are far lower than present-day estimates of the carbon embedded in usable reserves - some $2860 \mathrm{Gt}$, implying that two-thirds of present reserves of coal, oil and gas cannot be mined. This has fostered a new approach to carbon mitigation: to 'keep the oil in the soil' (Berners-Lee and Clark 2013).

$1 \mathrm{CO}_{2} \mathrm{e}$ stands for $\mathrm{CO}_{2}$ equivalent, or the amount of a given gas that would have the same warming potential as a tonne of $\mathrm{CO}_{2}$. 


\section{Adaptation}

Adaptation is defined by the IPCC as 'the process of adjustment to actual or expected climate and its effects' in both human and natural systems (IPCC 2014c). This process of adjustment differs according to regions and includes: the evolution of agricultural practices adapted to temperature; agroforestry to manage wildfires; land-use changes and settlement relocation; increased efficiency in water management systems; infectious disease control; wetland restoration and the maintenance of coastal landforms; enhanced monitoring, regulation and early warning systems for extreme weather events; stronger flood defences; the development of sustainable cities; and so on. This list excludes social adaptation measures such as building social capital and more resourceful communities able to withstand climate impacts.

An important distinction between the two policy domains must be noted here (Kolstad et al. 2014): mitigating GHG emissions is predominantly a 'global public good', whereas adaptation is more often a private or national good. Gains from adaptation (such as changing a crop to one more heat tolerant, or building flood defences) tend to be realised by the same parties or territories that are incurring the costs. There may be externalities involved, but these tend to be more localised and contemporaneous. ${ }^{2}$

The case of GHG mitigation is quite different: emissions in any geographical space will affect the global concentration everywhere. There are thus 'collective action problems'. 'Incentives for individuals or countries to unilaterally reduce emissions are considerably reduced; free-riding on the actions of others is a dominant strategy ... and lack of coordination yields insufficient mitigation' (IPCC 2014a). Elinor Ostrom's (1990) research on common pool resources concludes that efficient environmental management is more likely where four conditions hold: the environmental problem is visible; cause and effect relations are understood; the problem is reversible; and management results in clear net benefits to key constituencies. For many decades after the scientific community began to chart global warming none of these conditions applied to mitigating climate change, outside a few pioneers. Awareness of the first two is now growing as conditions worsen (Christoff and Eckersley 2013).

2 This of course by no means removes the presence of interests, power and realpolitik from the political economy of adaptation (Sovacool and Linnér 2016). 


\section{SOCIAL CONDITIONS AND HUMAN DEVELOPMENT}

Turning to the 'inner ring' of Raworth's (2012) lifebelt, I now summarise international and global efforts to map out the 'social' domain. What 'welfare' or 'wellbeing' consists of is discussed in detail in Chapter 2, but they certainly include concerns with health and survival chances, literacy and learning, access to essential resources and opportunities to participate in social life. The social dimension typically combines two things: a concern with levels of human wellbeing, and a concern with equity and justice - the way that wellbeing is distributed between peoples.

There is clear evidence of improved global wellbeing since the Second World War, as the 2015 Rockefeller Foundation-Lancet Report makes clear (Whitmee et al. 2015):

By most metrics, human health is better today than at any time in history. Life expectancy has soared from 47 years in 1950-1955, to 69 years in 2005-2010 . . The total number of people living in extreme poverty has fallen by 0.7 billion over the past 30 years, despite an increase in the total population of poor countries of about 2 billion. This escape from poverty has been accompanied by unparalleled advances in public health, health care, education, human rights legislation, and technological development that have brought great benefits, albeit inequitably, to humanity.

The United Nations Development Programme (UNDP) has developed a composite measure, the Human Development Index (HDI), that combines measures of health (life expectancy), learning (literacy and education) and resources to meet other basic needs (the log of GDP per head). This also charts significant improvements across the world, though less so in Africa.

Against this picture of progress, income inequality between countries widened throughout most of the twentieth century as the industrialising West pulled away from the rest of the world. It had also colonised much of that world or exercised economic power to prevent the emergence of serious competition. Only around the turn of the millennium did this trend reverse, when economic growth in the East really took off (Bocchiola 2013). However, since around 1980 inequality has begun to rise within most countries, in some at a rapid rate. This has renewed concerns over equity and justice and slowed down the rate of global average improvement in the HDI - by one-quarter from what it would otherwise be, according to the UNDP (2011).

Global concern with social conditions has taken many forms, including efforts to establish global social rights and agreed development goals. The 1948 UN Declaration on Human Rights comprised a wide range of 
civil and political rights but also certain economic and social rights: for example the rights to work, education and a standard of living adequate for health and wellbeing, including food, clothing, housing, medical care, necessary social services, and the right to security in the event of unemployment, sickness, disability, widowhood, old age or other lack of livelihood in circumstances beyond people's control (UN General Assembly 1948). This was followed by a further stream of declarations and conventions, many codified in the International Covenants on Civil and Political Rights (ICCPR) and Economic, Social and Cultural Rights (ICESR), both of which came into force in 1976. Since then, there have been the 1981 International Convention on the Elimination of All Forms of Discrimination against Women (ICEDAW), the 1989 Convention on the Rights of the Child and others. All of these include social and economic rights. However, implementation is soft, to say the least.

In 2000 the UN Millennium Development Goals (MDGs) were unanimously agreed by all 189 member states (Hulme and Scott 2010). Eight goals were set with 21 targets - for example to reduce by two-thirds by 2015 the under-five mortality rate; to halve, by 2015, the proportion of people without sustainable access to safe drinking water and basic sanitation - and more than 60 indicators were agreed to chart progress. They amount to 'a minimum set of global social standards in education, health and poverty alleviation' (Deacon 2007: 173). The poverty target has been achieved (ten years early) but not that for malnutrition. The gender equality goal was achieved and the education goal narrowly missed. However, the health goals were not met.

\section{TOWARDS SUSTAINABLE DEVELOPMENT?}

The global picture painted so far charts three diverging trends: first, significant progress in some core features of social conditions and human development across the globe; second, rising inequalities; and, third, an as yet uncontrolled accumulation of greenhouse gases that will drive future global warming with significant damaging consequences for habitats and human welfare.

The following questions arise:

- What are the implications of climate change for future human welfare?

- How will the pursuit of climate stability interact with the pursuit of social improvement?

- Can we achieve some combination of equity/justice and sustainability? 
These questions lie at the heart of this book.

It is interesting that two reports approaching the question from opposite directions come to roughly the same conclusion. The 2005 Millennium Ecosystem Assessment (Corvalan et al. 2005) concluded that, over the past 50 years, humans have changed ecosystems more rapidly and extensively than in any comparable period of time in human history, largely to meet rapidly growing demands for food, fresh water, timber, fibre, ores and fuel. This has resulted in a substantial and largely irreversible loss in the diversity of life on Earth. There have been substantial net gains in human wellbeing and economic development, but these gains have been achieved at growing costs in terms of the degradation of many 'ecosystem services', increased risks of non-linear changes, and the exacerbation of poverty for some groups of people. These problems, unless addressed, seriously threaten future human wellbeing.

The 2015 Rockefeller Foundation-Lancet Commission, writing about health and climate change, summarises recent decades of the relationship between welfare and sustainability as follows:

We have been mortgaging the health of future generations to realize economic and development gains in the present. By unsustainably exploiting nature's resources, human civilisation has flourished but now risks substantial health effects from the degradation of nature's life support systems in the future . . In essence, humanity has traded off many of the Earth's supportive and regulating processes to feed and fuel human population growth and development.

Looking ahead, the 2011 UNDP Report presents two simulations of the effect of unmitigated climate change on human development as measured by the HDI (not GDP) (see Figure 1.3). The first, the 'environmental challenge' scenario, models the adverse effects of global warming on agricultural production, on pollution and on access to clean water and improved sanitation. It suggests that by 2050 the global HDI would be 8 per cent lower than in the baseline case (and 12 per cent lower in South Asia and sub-Saharan Africa). A second, even more adverse, 'environmental disaster' scenario envisages extensive deforestation and land degradation, dramatic declines in biodiversity and accelerated extreme weather events. Here, global HDI would be some 15 per cent below the baseline. It would lead to a turning point before 2050 in poorer developing countries: their slow convergence with rich countries in HDI achievements would turn into an absolute decline.

Global policy responses to this twin threat can be dated back to the 1987 Brundtland Report on sustainable development and to the 1992 UN Rio Earth Summit. The former's famous definition of sustainable development - headlined in Chapter 2 below - provides an optimistic 


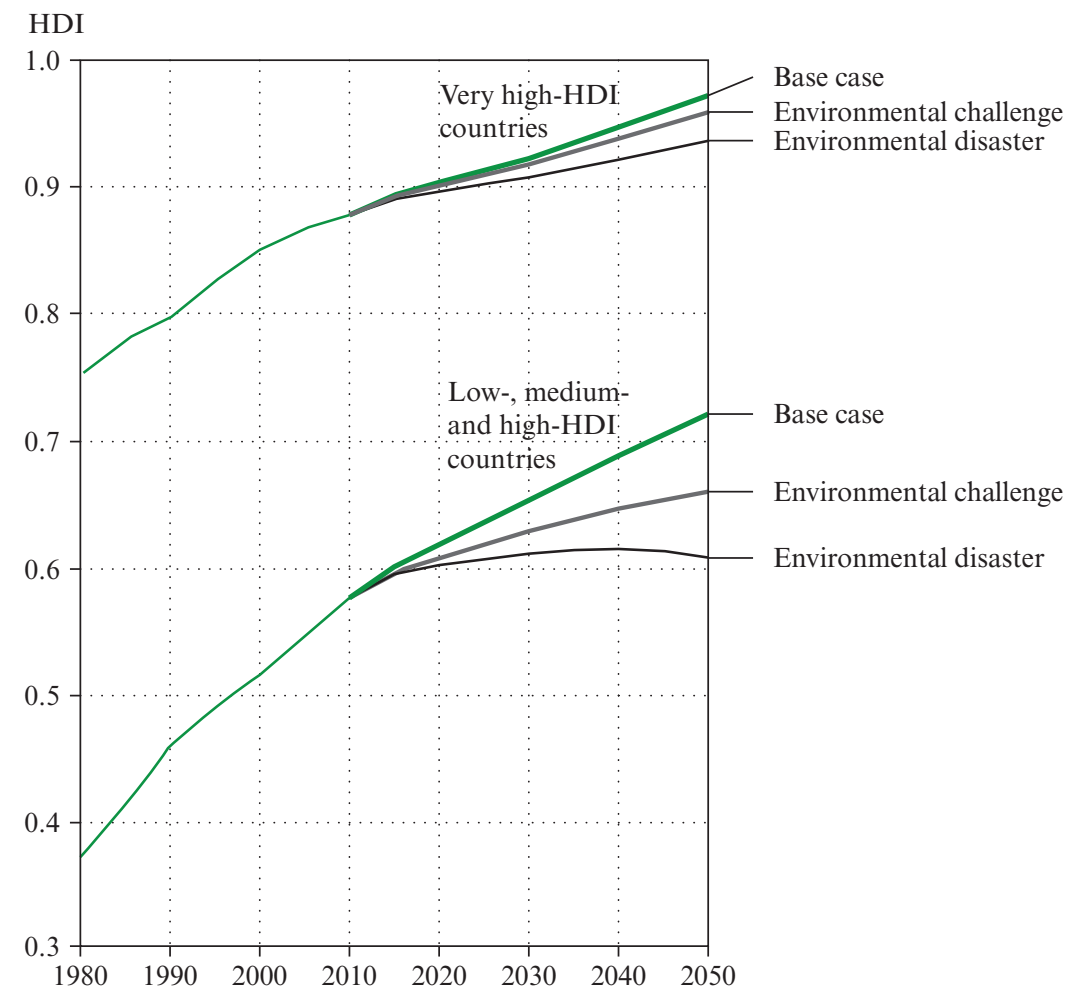

Source: UNDP (2011: 31).

Figure 1.3 Scenarios projecting impacts of environmental risks on human development to 2050

vision of a common goal for all humanity and forms the basis of a core argument in this book. The UN Rio Earth Summit in 1992 followed it up with a quite radical statement of normative principles to guide global environmental and climate change policy. These included the precautionary principle (Principle 15), the 'polluter pays' principle (Principle 16) and Principle 7 on 'common but differentiated responsibilities' between developed and developing countries (Christoff and Eckersley 2013).

But realising all this in practice since the Rio Summit has proved extremely difficult. The discourse of sustainable development has been interpreted as a political construct designed to facilitate a bargain across the deep structural divide between North and South (Vogler 2007). In simplistic terms, the North did not want to recognise the role of high 
incomes and consumption in climate change, while the South wanted to avoid association with population growth. What was left and could be agreed upon was, as always, technology and the role of human ingenuity in extracting more and more growth with fewer and fewer emissions. Twenty years later at the Rio +20 conference, sustainable development had been displaced by the weaker bridging concept of 'green growth': a strategy to decarbonise today's economies but within a capitalist framework committed to economic growth. The change from 'sustainable development' of Rio 1992 marked a shift from an environmental to a more economic discourse (see Chapter 3).

\section{5: New York and Paris}

Two notable global agreements occurred in 2015: the unanimous adoption at the UN in New York of the Sustainable Development Goals (SDGs) and the Paris agreement in December on greenhouse gas emissions within the UNFCCC. Does this mark a new turn towards a sustainable pathway for people and planet?

The ambition of the SDGs has been described as 'breath-taking': a list of 17 goals and 169 targets, it is arguably the most comprehensive global agenda adopted since the UN Charter in 1945. Its thematic repertoire ranges from poverty, health, education and inequality through to energy, infrastructure, climate change, marine resources, peace, security and good governance. The goals have been criticised by Charles Kenny of the Center for Global Development as unmanageable, 'overwrought and obese': monitoring progress will be all but impossible and will encourage picking and choosing between the 169 targets.

Yet the UN Secretary-General welcomed the agenda by saying it 'encompasses a universal, transformative and integrated agenda that heralds an historic turning point for our world' (Fukuda-Parr 2015; Langford 2016). Unlike the MDGs, many targets apply to the North as well as to the South. The agenda is also ambitious: for example, one goal is to abolish poverty by 2030, not to reduce it. The agreement of 193 countries may perhaps signal the emergence of a broader normative consensus. Above all, the SDGs begin to take the social conditions of future generations seriously. Global warming brings intergenerational welfare, equity and justice centre-stage. Failure to counteract it will threaten the wellbeing of future generations, albeit in varied and unequal ways.

The 2015 SDG agenda concurs with the 2014 IPCC Report in recognising that some mitigation efforts can and do undermine actions to pursue equity or eradicate poverty: a comprehensive assessment of climate policies means evaluating the sustainability and equity of development 
pathways more generally (IPCC 2014c: 5). As the Brundtland Report (WCED 1987) definition makes clear, it is not acceptable to provide for current welfare at the expense of future welfare. But nor is it acceptable to provide for future welfare at the expense of the current welfare of the poor of the world. The SDG agenda arguably begins the process of relating - if not reconciling - environmental sustainability with social justice.

In late 2015 the Paris climate conference (COP) achieved a treaty agreement on several key issues, of which two are worth noting here. First, all states have clearly accepted the ultimate goal of net zero emissions, to be achieved 'in the second half of this century'. Second, every five years a stocktake will take place showing how far current emissions projections diverge from a $2{ }^{\circ} \mathrm{C}$ - and a $1.5^{\circ} \mathrm{C}$ - pathway. Two years after each stocktake, all countries will have to produce, for the subsequent 10 - or 15-year period, new targets and plans that are 'more ambitious' than the last. Countries' commitments are not legally binding, but the requirement to improve national plans every five years is legally binding. This architecture is designed to send clear signals to business, investors and governments that the future direction of the global economy is low carbon.

The agreement was ratified in November 2016, by which time 55 nations accounting for at least 55 per cent of total global GHGs deposited their articles of ratification with the United Nations. Opinions about the Paris COP of December 2015 vary widely. According to many participants and commentators the outcome was impressive: 'the Agreement lies at almost the highest level of ambition that could possibly have been achieved' (Jacobs 2015).

For others the Paris agreement is too little, too late. The American environmental activist Bill McKibben, for example, commented:

the world emerges, finally, with something like a climate accord, albeit unenforceable. If all parties keep their promises, the planet would warm by an estimated 3.5 degrees Celsius ... and that is way, way too much ... The irony is, an agreement like this adopted at the first climate conference in 1995 might have worked. (McKibben 2015)

Critical environmentalist Clive Spash (2016) is uncompromising: 'The Paris agreement changes nothing ... it treats worst case scenarios as an acceptable 50:50 chance ... the targets and promises of the Paris Agreement bear no relationship to biophysical or social and economic reality.'

Perhaps the environmental journalist George Monbiot (2015) sums this up best: 'By comparison to what it could have been, it's a miracle. By comparison to what it should have been, it's a disaster.' 


\section{CONCLUSION}

Climate change cannot be the basic cause of poverty, ill-health, unmet basic needs and fragile livelihoods; these have existed throughout human history. But the hazards of uncontrolled climate change constitute an epochal 'threat multiplier'. It will make the pursuit of economic and social needs and rights more difficult and, if global warming exceeds a threshold around $2{ }^{\circ} \mathrm{C}$, then it will overwhelm all attempts to eradicate poverty, let alone provide all peoples with an acceptable level of security and a flourishing life.

The goal must be to respect biophysical boundaries while at the same time pursuing sustainable wellbeing: that is, wellbeing for all current peoples and for future generations. An acceptable and sufficient level of human wellbeing also means paying attention to its distribution between peoples. Issues of equity and social justice are central. The social dimension of climate change thus refers to both the average level of human wellbeing in any specific dimension and its just distribution. Both, together with respecting biophysical boundaries, are necessary for 'sustainable wellbeing'.

In summary, the pursuit of wellbeing and social justice is inadequate if it is at the expense of the biosphere and future generations. At the same time, the pursuit of human wellbeing for some while also respecting planetary limits is unacceptable if it is at the expense of global justice and the poor of the world. Similarly, the pursuit of social justice within planetary limits is inadequate if justice is understood solely in procedural terms, such as greater civic rights and Western democracy, while ignoring more material aspects of wellbeing.

This book focuses on the interrelation between three goals: wellbeing and social justice within planetary boundaries. It considers what might be done to advance all three together. 